\title{
Safety and efficacy of the addition of pertuzumab to T-DMI \pm taxane in patients with HER2-positive, locally advanced or metastatic breast cancer: a pooled analysis
}

\author{
This article was published in the following Dove Press journal: \\ Drug Design, Development and Therapy \\ 15 November 2017 \\ Number of times this article has been viewed
}

Jing Zhang ${ }^{1,2, *}$

Jinying $\mathrm{Li}^{3}$

Chenjing Zhu'

Yanlin Song'

Fan Xia'

Xuelei Ma ${ }^{1, *}$

'Cancer Center, West China Hospital, Collaborative Innovation Center for Biotherapy, ${ }^{2}$ Department of Neurosurgery, West China Hospital, Sichuan University, Chengdu, ${ }^{3}$ The Second Affiliated Hospital of Medical College of Qingdao University, Qingdao Central Hospital, Qingdao, People's Republic of China

*These authors contributed equally to this work
Correspondence: Xuelei Ma Cancer Center, West China Hospital, No 37 Guoxue Alley, Chengdu 61004I, Sichuan, People's Republic of China Email drmaxuelei@gmail.com
Background: The aim of this review was to systematically evaluate the safety and efficacy of the addition of pertuzumab to trastuzumab emtansine (T-DM1) \pm taxane in patients with human epidermal growth factor receptor 2 (HER2)-positive, locally advanced breast cancer (LABC) or metastatic breast cancer (MBC).

Materials and methods: Several databases were searched for relevant clinical trials. The study characteristics, details of adverse events (AEs) and details of treatment efficacy were extracted for analysis.

Results: Six studies with 996 patients were included. Common AEs of T-DM1 + pertuzumab \pm taxane included fatigue, diarrhea, nausea, epistaxis, peripheral neuropathy, increased aspartate transaminase (AST), increased alanine transaminase (ALT) and thrombocytopenia. Major grade $\geq 3$ AEs of T-DM1 + pertuzumab \pm taxane included thrombocytopenia, neutropenia, fatigue, increased ALT, anemia and peripheral neuropathy. The addition of pertuzumab to T-DM1 \pm taxane led to higher risks of diarrhea (especially grade $\geq 3$ diarrhea), rash and vomiting, and decreased risks of thrombocytopenia and grade $\geq 3$ increased AST. The relative risks of the addition of pertuzumab to T-DM1 \pm taxane for objective response (1.068, 95\% CI 0.945-1.207) and clinical benefit $(1.038,95 \%$ CI $0.974-1.106)$ were not statistically significant.

Conclusion: Common AEs should be carefully monitored in HER2-positive LABC or MBC patients treated with T-DM1 + pertuzumab \pm taxane. The addition of pertuzumab to T-DM1 \pm taxane showed noninferior, but not superior, objective response rate and clinical benefit rate. However, more studies are needed to further verify these findings.

Keywords: trastuzumab emtansine, pertuzumab, human epidermal growth factor receptor 2, breast cancer, adverse events, efficacy

\section{Introduction}

HER2 is overexpressed in $15 \%-20 \%$ of breast cancers. ${ }^{1,2}$ Trastuzumab, a HER2targeted monoclonal antibody, increases the clinical benefit of chemotherapy in patients with HER2-positive metastatic breast cancer (MBC). ${ }^{3}$ Antibody-drug conjugates (ADCs) combine targeted antibodies with cytotoxic drugs to minimize systemic toxicity and improve therapeutic index of chemotherapy. ${ }^{4,5}$ Trastuzumab emtansine (T-DM1) is an ADC composed of trastuzumab conjugated to the microtubule polymerization inhibitor DM1 via a stable linker. ${ }^{5}$ Like trastuzumab, T-DM1 inhibits HER2 shedding, blocks HER2 signaling and activates antibody-dependent cellular cytotoxicity. ${ }^{6}$ In two Phase III studies, T-DM1 resulted in improved efficacy and tolerability versus 
standard therapy in patients with previously treated HER2positive MBC. ${ }^{7,8}$

Pertuzumab is also a monoclonal antibody binding to a different HER2 domain from trastuzumab and induces antibody-dependent cell-mediated cytotoxicity as well. ${ }^{9}$ The addition of pertuzumab to trastuzumab + docetaxel has demonstrated significant improvements in progression-free survival (PFS) and overall survival (OS) in patients with previously untreated HER2-positive MBC. ${ }^{10,11}$ Previous preclinical studies showed that pertuzumab could enhance the antitumor activity of T-DM $1 .{ }^{12}$ Recently, several clinical trials were published to examine the safety and efficacy of the addition of pertuzumab to T-DM1 \pm taxane in patients with HER2-positive, locally advanced breast cancer (LABC) or MBC. ${ }^{13-15}$

The aim of this review was to systematically evaluate the safety and efficacy of the addition of pertuzumab to T-DM1 \pm taxane in patients with HER2-positive LABC or MBC through performing a meta-analysis.

\section{Materials and methods}

\section{Search strategy}

We followed the guidelines for performing meta-analyses in our study. ${ }^{16}$ We searched PubMed, EMBASE, Cochrane Library, China National Knowledge Infrastructure (CNKI) and ClinicalTrials.gov (http://www.ClinicalTrials.gov) for relevant clinical trials (up to March 23, 2017). The following terms were used: "ado-trastuzumab emtansine," "pertuzumab" and "breast neoplasms." Reference lists of relevant articles were also screened for additional studies. No language restriction was used.

\section{Study selection}

Two reviewers (JZ and CZ) independently performed the study selection process, with any disagreements being discussed. The inclusion criteria included the following: 1) the studies were clinical trials in any phase; 2 ) the studies evaluated the safety and efficacy of the addition of pertuzumab to T-DM1 \pm taxane in patients with HER2-positive LABC or MBC; 3) the relevant data of adverse events (AEs) and treatment efficacy were available. Unrelated articles, retrospective studies, reviews, case reports, letters and studies without necessary data were excluded.

\section{Data extraction}

Two experienced researchers (JZ and CZ) independently extracted relevant data from the included studies, and discrepancies were resolved by consensus. The primary data included the characteristics of AEs, objective response rate (ORR), clinical benefit rate (CBR), complete response $(\mathrm{CR})$ rate, partial response (PR) rate, stable disease (SD) rate, progressive disease (PD) rate and median PFS. The study and patient characteristics included first author, publication year, country, median age of patients, gender, study phase and treatment regimen.

\section{Statistical analysis}

The rates of AEs (both all-grade AEs and grade $\geq 3$ AEs) and $95 \%$ CI were calculated from both single-arm studies and controlled trials. For controlled trials, the relative risks (RRs) of AEs (both all-grade AEs and grade $\geq 3$ AEs) and treatment efficacy (ORR and CBR) were compared between the treatment arm and control arm. Significance was determined at $P<0.05$. Statistical heterogeneity was defined as $I^{2}>50 \%$ and $P \leq 0.1$. Random-effects models were used if the heterogeneity existed. All the abovementioned analyses were performed by Comprehensive Meta-Analysis (CMA) program 2 (Biostat, Englewood, NJ, USA). The risks of bias of the included studies were also measured using RevMan, version 5.2. ${ }^{20}$ The items included random sequence generation (selection bias), allocation concealment (selection bias), blinding of participants and personnel (performance bias), blinding of outcome assessment (detection bias), incomplete outcome data (attrition bias), selective reporting (reporting bias) and other biases. The risks of bias were rated as low/ unclear/high.

\section{Results}

\section{Literature search}

The initial search yielded 734 studies. After removing duplicates, 627 studies were screened for eligibility. According to the inclusion and exclusion criteria, 604 studies were excluded. The remaining 23 studies were assessed in full text. A total of 17 studies were further excluded, and six studies $^{12-15,17,18}$ were finally included in our meta-analysis. The selection process is shown in Figure 1.

\section{Study characteristics}

These studies were published from 2013 to 2017. A total of 996 patients were included, and all of them were female except for one male. The studies were all multicenter clinical trials, including two randomized controlled trials (RCTs; Phase Ib/IIa and Phase III), two nonrandomized trials (Phase II and Phase Ib/IIa) and two single-arm studies (Phase IIa and Phase Ib/II). Among the 


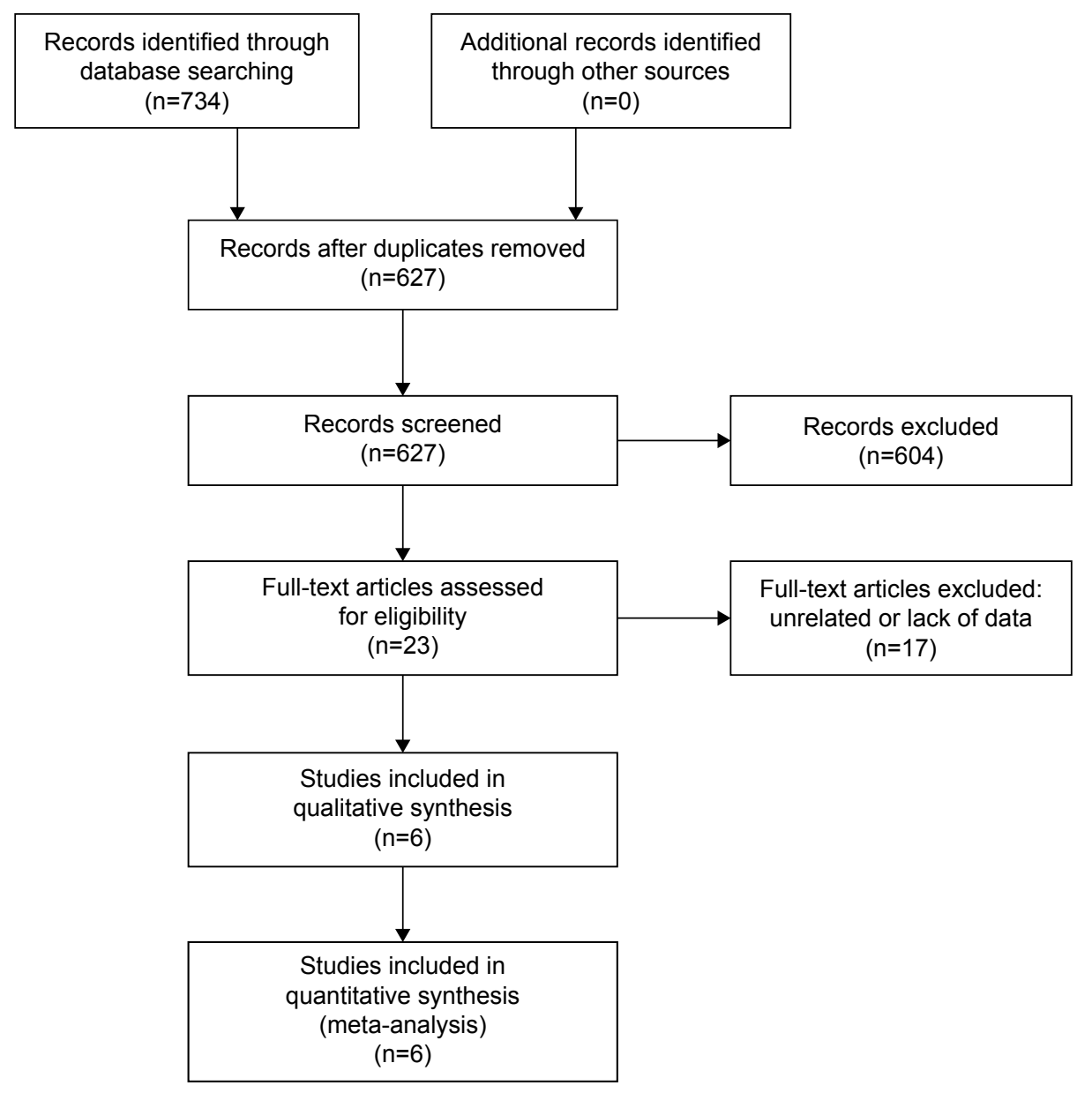

Figure I Flow diagram of the literature search and selection process.

studies, the dose of T-DM1 was $3.6 \mathrm{mg} / \mathrm{kg} \mathrm{q} 3 \mathrm{w}$, except for four patients $(3.0 \mathrm{mg} / \mathrm{kg} \mathrm{q} 3 \mathrm{w})$ in the study by Phillips et al. ${ }^{12}$ The doses of pertuzumab in the six studies were all $840 \mathrm{mg}$ loading dose followed by $420 \mathrm{mg}$ q3 w. The treatment regimens and other details are summarized in Table 1.

\section{Safety analysis of the addition of pertuzumab to T-DMI \pm taxane}

To investigate the rates of all-grade and grade $\geq 3$ AEs, the data in the single-arm studies and controlled trials were pooled (Figures 2 and 3). Among all-grade AEs, the highest rate was found for fatigue $(55.9 \%$, 95\% CI 32.6\%-76.8\%, random-effects model). Diarrhea $(37.8 \%, 95 \%$ CI $21.5 \%-57.4 \%)$, nausea $(37.8 \%$, 95\% CI $22.7 \%-55.7 \%)$, epistaxis $(36.2 \%, 95 \%$ CI $21.4 \%-54.3 \%)$ and peripheral neuropathy $(30.2 \%, 95 \%$ CI $13.6 \%-54.4 \%$ ) were also common all-grade AEs in random-effects models. In fixed-effects models, common all-grade AEs included increased aspartate transaminase
(AST; 23.7\%, 95\% CI 16.2\%-33.4\%), increased alanine transaminase (ALT; 22.6\%, 95\% CI 15.2\%-32.2\%) and thrombocytopenia $(21.7 \%$, 95\% CI 15.4\%-29.8\%). As to grade $\geq 3$ AEs, thrombocytopenia $(14.5 \%, 95 \% \mathrm{CI}$ $10.9 \%-19.0 \%$ ) was the most frequent (fixed-effects model). Other common grade $\geq 3$ AEs in fixed-effects models included fatigue (12.8\%, 95\% CI 7.8\%-20.3\%), increased ALT (11.4\%, 95\% CI 8.1\%-15.8\%) and anemia (10.9\%, 95\% CI 7.7\%-15.3\%). Neutropenia (13.4\%, 95\% CI 5.2\%-30.6\%) and peripheral neuropathy (10.4\%, 95\% CI 1.0\%-56.3\%) were common grade $\geq 3$ AEs in random-effects models.

For controlled trials, the RRs of all-grade and grade $\geq 3$ AEs between the treatment arm and control arm were calculated (Figures 4 and 5). Among all-grade AEs, increased risks of diarrhea ( $\mathrm{RR}=1.885,95 \%$ CI 1.566-2.268), $\operatorname{rash}(\mathrm{RR}=1.477,95 \% \mathrm{CI} 1.136-1.921)$ and vomiting $(\mathrm{RR}=1.291,95 \%$ CI 1.030-1.616) were found in the treatment arm (fixed-effects model). The treatment arm was associated with a decreased risk of all-grade thrombocytopenia 
Table I Basic characteristics of the included studies

\begin{tabular}{|c|c|c|c|c|c|c|c|c|}
\hline Study & Year & $\begin{array}{l}\text { Median age } \\
\text { (years) }\end{array}$ & $\mathbf{N}(\mathbf{F} / \mathbf{M})$ & Design & Phase & Treatment arm & Control arm & Indications \\
\hline $\begin{array}{l}\text { Gupta } \\
\text { et al }{ }^{17}\end{array}$ & 2013 & 52 & $5 \mathrm{I}(5 \mathrm{I} / 0)$ & $\begin{array}{l}\text { Multicenter, } \\
\text { nonrandomized }\end{array}$ & Phase II & $\begin{array}{l}\text { T-DMI + pertuzumab } \\
(\mathrm{n}=20)\end{array}$ & T-DMI $(n=5 I)$ & $\begin{array}{l}\text { HER2-positive } \\
\text { LABC or MBC }\end{array}$ \\
\hline $\begin{array}{l}\text { Krop } \\
\text { et al }{ }^{13}\end{array}$ & 2016 & 52.5 & $44(43 / I)$ & $\begin{array}{l}\text { Multicenter, } \\
\text { RCT }\end{array}$ & Phase lb/lla & $\begin{array}{l}\text { T-DMI + pertuzumab + } \\
\text { paclitaxel }(n=22)\end{array}$ & $\begin{array}{l}\text { T-DMI + } \\
\text { paclitaxel }(n=22)\end{array}$ & $\begin{array}{l}\text { HER2-positive } \\
\text { LABC or MBC }\end{array}$ \\
\hline $\begin{array}{l}\text { Martin } \\
\text { et al }{ }^{14}\end{array}$ & 2016 & $\begin{array}{l}\text { Control: } 47 \\
\text { Treatment: } 52\end{array}$ & $98(98 / 0)$ & $\begin{array}{l}\text { Multicenter, } \\
\text { nonrandomized }\end{array}$ & Phase lb/lla & $\begin{array}{l}\text { T-DMI + pertuzumab + } \\
\text { docetaxel }(n=33)\end{array}$ & $\begin{array}{l}\text { T-DMI + } \\
\text { docetaxel }(n=65)\end{array}$ & $\begin{array}{l}\text { HER2-positive } \\
\text { LABC or MBC }\end{array}$ \\
\hline $\begin{array}{l}\text { Perez } \\
\text { et al }\left.\right|^{15}\end{array}$ & 2017 & 52 & $730(730 / 0)$ & $\begin{array}{l}\text { Multicenter, } \\
\text { RCT }\end{array}$ & Phase III & $\begin{array}{l}\text { T-DMI + pertuzumab } \\
(n=363)\end{array}$ & T-DMI $(n=367)$ & $\begin{array}{l}\text { HER2-positive } \\
\text { LABC or MBC }\end{array}$ \\
\hline $\begin{array}{l}\text { Miller } \\
\text { et al }{ }^{18}\end{array}$ & 2014 & 54 & $64(64 / 0)$ & $\begin{array}{l}\text { Multicenter, } \\
\text { single-arm }\end{array}$ & Phase Ila & $\begin{array}{l}\text { T-DMI + pertuzumab } \\
(\mathrm{n}=64)\end{array}$ & - & $\begin{array}{l}\text { HER2-positive } \\
\text { LABC or MBC }\end{array}$ \\
\hline $\begin{array}{l}\text { Phillips } \\
\text { et al }{ }^{12}\end{array}$ & 2014 & 55 & $9(9 / 0)$ & $\begin{array}{l}\text { Multicenter, } \\
\text { single-arm }\end{array}$ & Phase Ib/II & $\begin{array}{l}\text { T-DMI + pertuzumab } \\
(\mathrm{n}=9)\end{array}$ & - & $\begin{array}{l}\text { HER2-positive } \\
\text { LABC or MBC }\end{array}$ \\
\hline
\end{tabular}

Abbreviations: $F$, female; HER2, human epidermal growth factor receptor 2; LABC, locally advanced breast cancer; $M$, male; $M B C$, metastatic breast cancer; $R C T$, randomized controlled trial; T-DMI, trastuzumab emtansine.

(RR $=0.563$, 95\% CI 0.329-0.964, fixed-effects model). The RRs of the five all-grade AEs in random-effects models were all not statistically significant. The seven grade $\geq 3$ AEs were all pooled in fixed-effects models.
The treatment arm was associated with an increased risk of grade $\geq 3$ diarrhea $(\mathrm{RR}=7.047,95 \%$ CI 1.583-31.382) and a decreased risk of grade $\geq 3$ increased AST $(\mathrm{RR}=0.507$, 95\% CI 0.279-0.923).

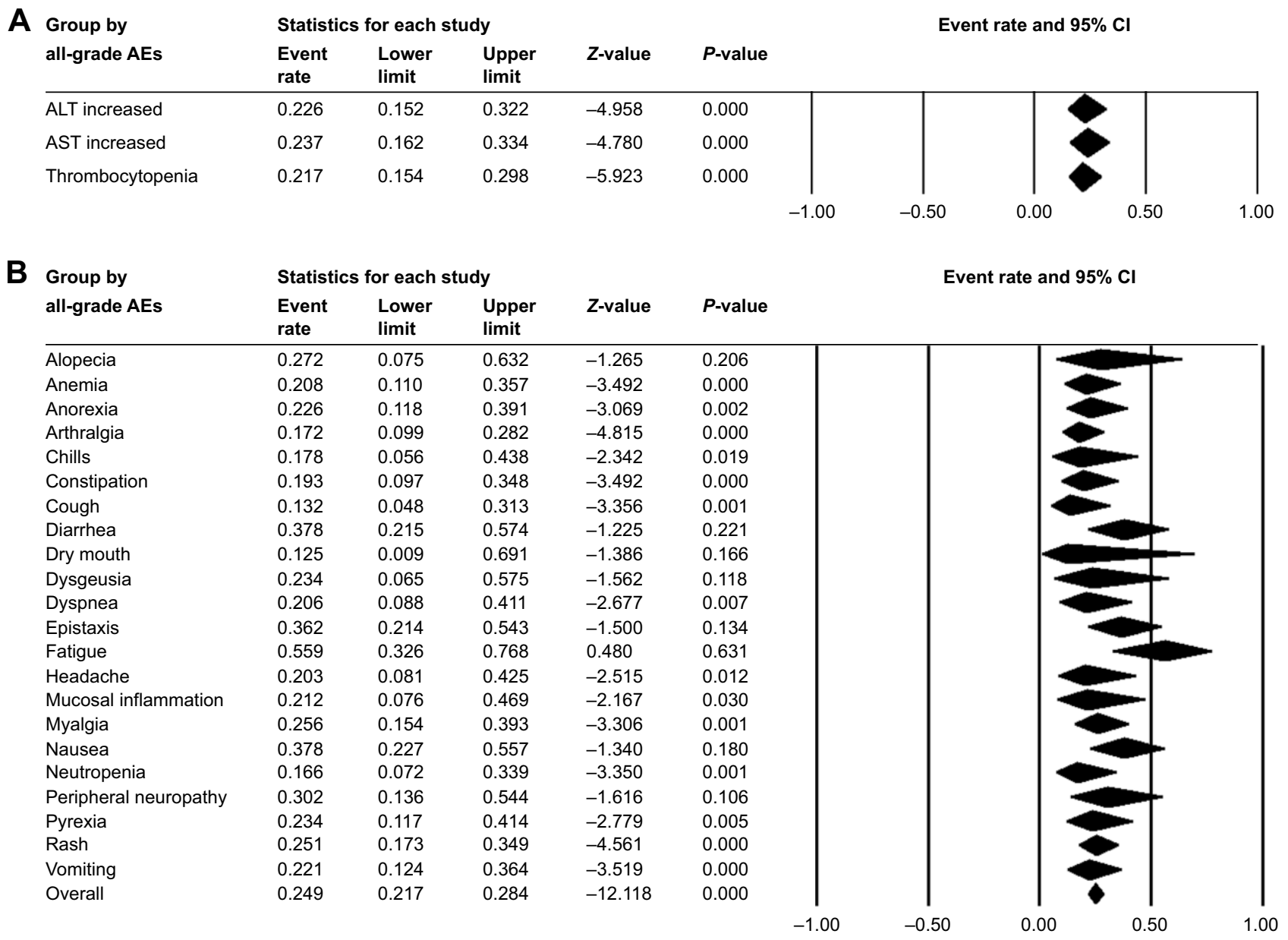

Figure 2 Forest plots of the rates of all-grade AEs of T-DMI + pertuzumab \pm taxane, fixed-effects model (A) and random-effects model (B). Abbreviations: AEs, adverse events; ALT, alanine transaminase; AST, aspartate transaminase; T-DMI, trastuzumab emtansine. 


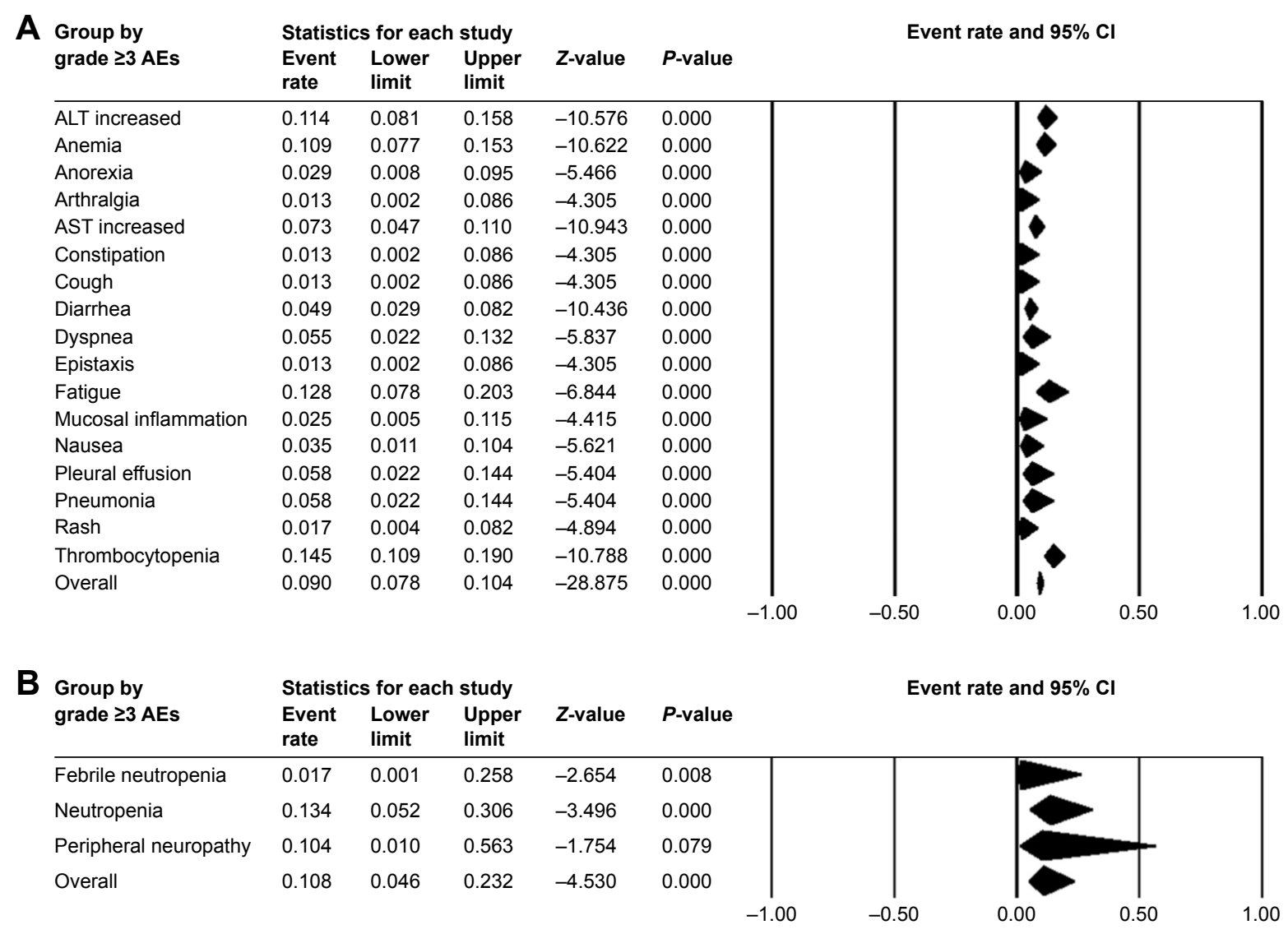

Figure 3 Forest plots of the rates of grade $\geq 3$ AEs of T-DMI + pertuzumab \pm taxane, fixed-effects model (A) and random-effects model (B). Abbreviations: AEs, adverse events; ALT, alanine transaminase; AST, aspartate transaminase; T-DMI, trastuzumab emtansine.

\section{Efficacy analysis of the addition of pertuzumab to T-DMI \pm taxane}

The outcomes of the patients in each study are summarized in Table 2. As to the controlled trials, the RRs of the ORR and CBR between the treatment arm and control arm were pooled (Figure 6). The results showed that the RRs of the ORR (1.068, 95\% CI 0.945-1.207, fixed-effects model) and the CBR (1.038, 95\% CI 0.974-1.106, fixed-effects model) were not statistically significant.

\section{Risk of bias}

The risk of bias graph and risk of bias summary of the four controlled trials are outlined in Figure 7. The overall risk of bias was evaluated as low risk.

\section{Discussion}

To the best of our knowledge, this is the first meta-analysis that assesses the safety and efficacy of the addition of pertuzumab to T-DM1 \pm taxane in patients with HER2-positive LABC or MBC. Our results showed that major AEs of T-DM1 + pertuzumab \pm taxane included fatigue, diarrhea, nausea, epistaxis, peripheral neuropathy, increased AST, increased
ALT and thrombocytopenia. Major grade $\geq 3$ AEs of T-DM1 + pertuzumab \pm taxane included thrombocytopenia, neutropenia, fatigue, increased ALT, anemia and peripheral neuropathy. The addition of pertuzumab to T-DM1 \pm taxane led to higher risks of diarrhea (especially grade $\geq 3$ ), rash and vomiting, and decreased risks of thrombocytopenia and grade $\geq 3$ increased AST. As to efficacy, the addition of pertuzumab to T-DM1 \pm taxane showed noninferior, but not superior, ORR and CBR.

In our safety analysis, fatigue was the most common $\mathrm{AE}$ (55.9\%). However, among the included studies, the incidence of fatigue varied from $20 \%$ to $86 \%,{ }^{12-14,17,18}$ with high incidences in the studies by Krop et $\mathrm{al}^{13}(86 \%)$, Phillips et al ${ }^{12}$ (78\%) and Martin et al ${ }^{14}(61 \%)$. The possible explanation may be that the studies by Krop et al and Martin et al used paclitaxel or docetaxel in addition to T-DM1 plus pertuzumab respectively, and taxane use could cause neurotoxicity. ${ }^{19}$ In addition, the sample number in the study by Phillips et al is very small (nine patients). Besides, the event rate of peripheral neuropathy in the study by Krop et al (91\%) was much higher than that in other studies, which may be also attributed to the addition of paclitaxel. Of note, our results showed that 
A

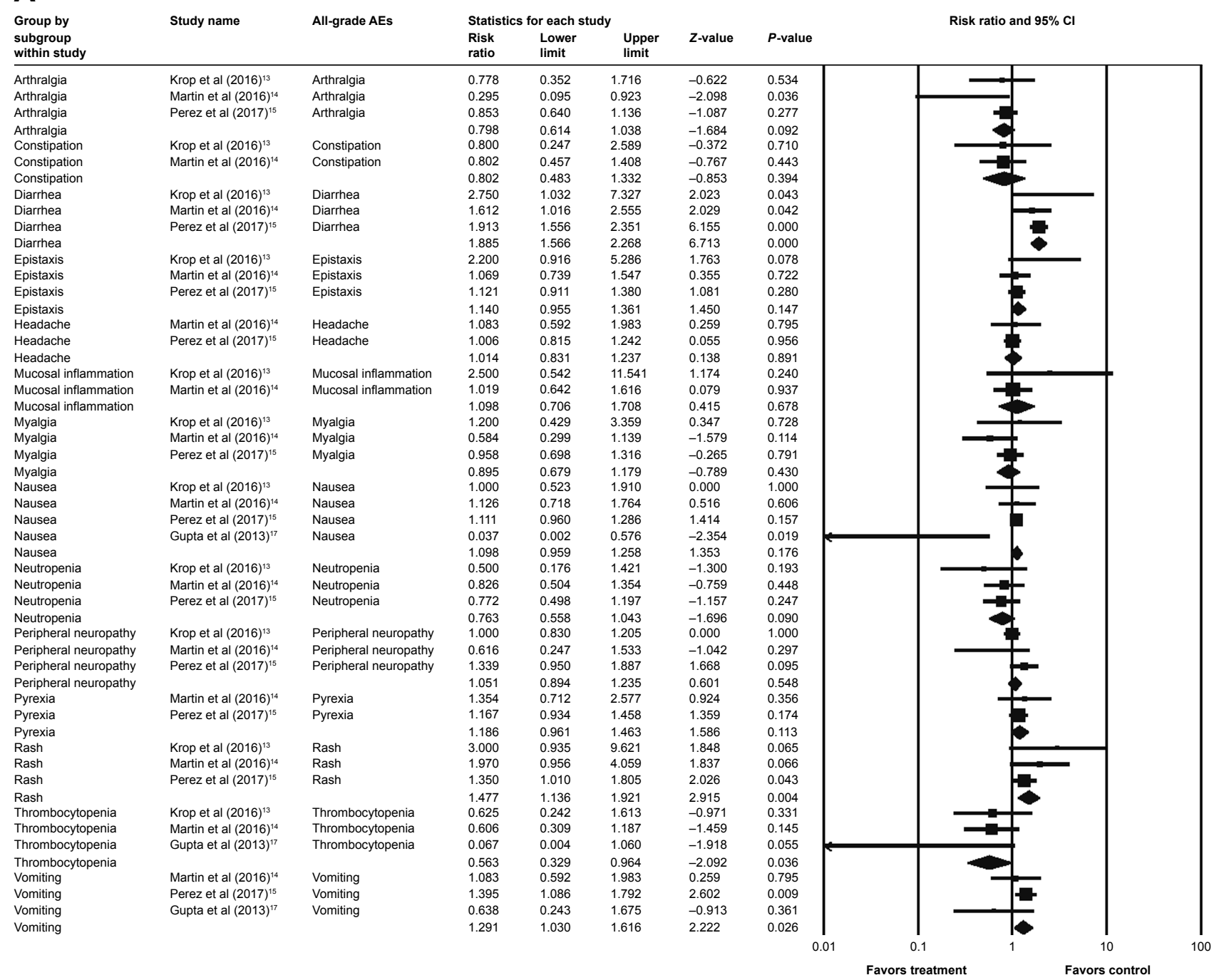

B

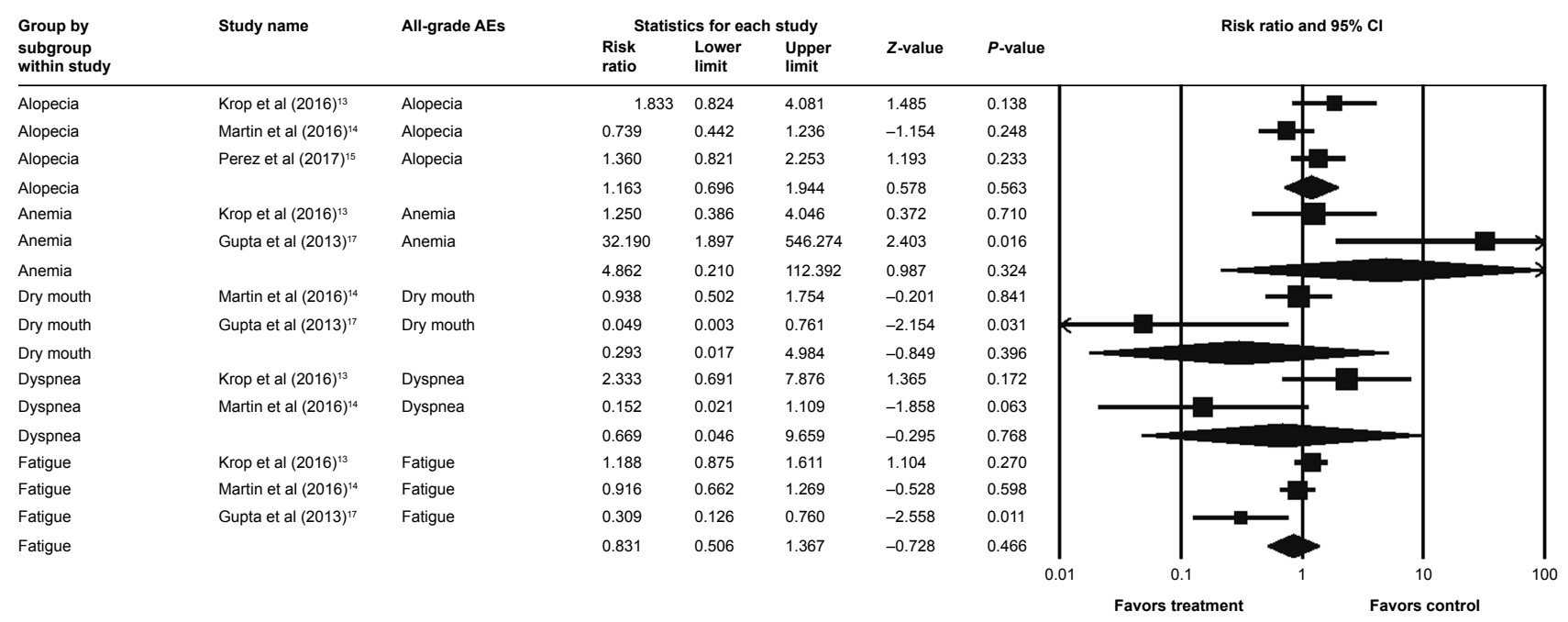

Figure 4 Forest plots of the RRs of all-grade AEs comparing the treatment group and control group (without pertuzumab) in controlled trials, fixed-effects model (A) and random-effects model (B).

Abbreviations: AEs, adverse events; ALT, alanine transaminase; AST, aspartate transaminase; RRs, relative risks. 


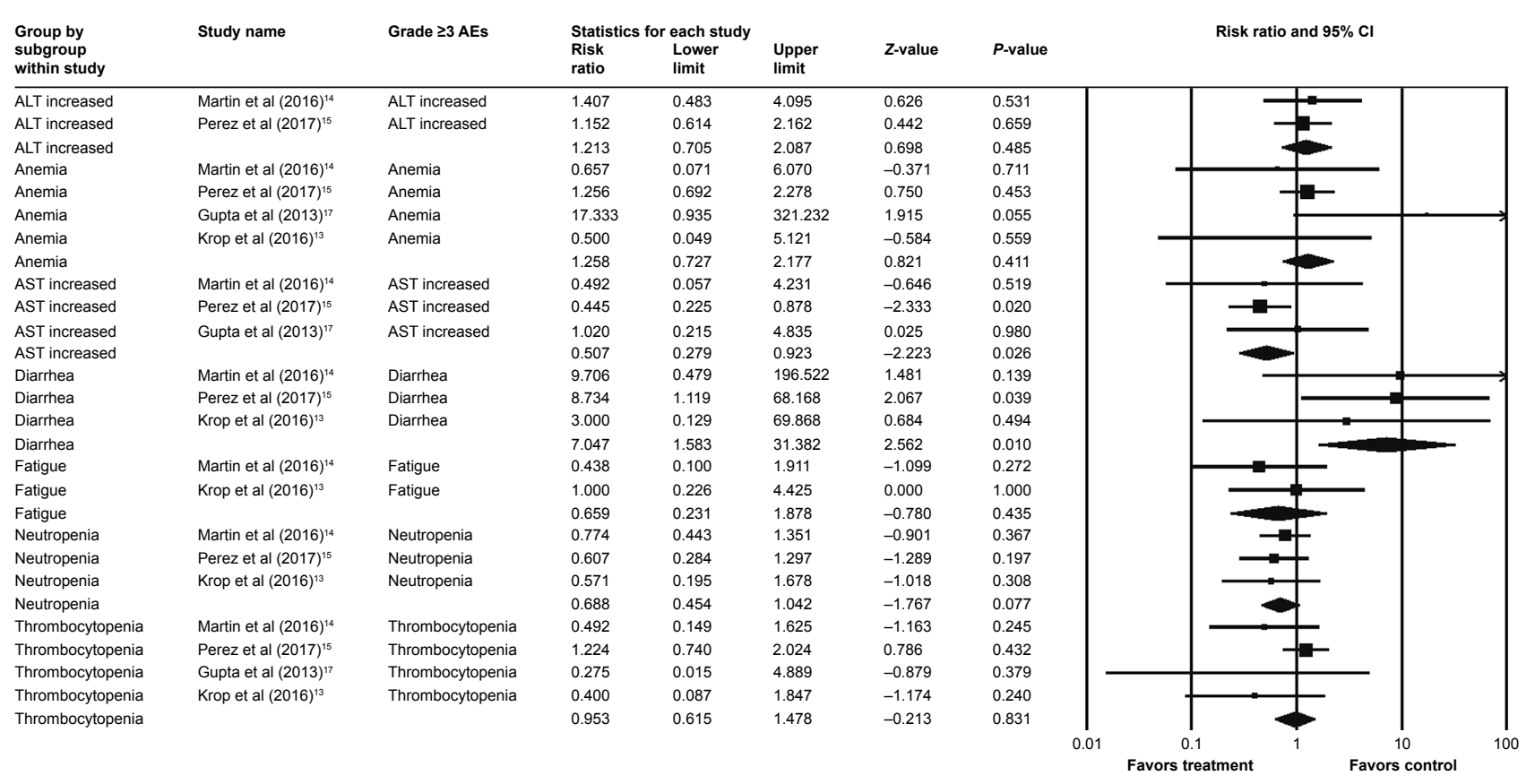

Figure 5 Forest plots of the RRs of grade $\geq 3 \mathrm{AEs}$ comparing the treatment group and control group (without pertuzumab) in controlled trials (fixed-effects model). Abbreviations: AEs, adverse events; ALT, alanine transaminase; AST, aspartate transaminase; RRs, relative risks.

hematologic disorders, such as thrombocytopenia, anemia and neutropenia, were common grade $\geq 3$ AEs in patients treated with T-DM1 + pertuzumab \pm taxane, making it more important to monitor blood tests during therapy. After pooling the data in the controlled trials, we found that the addition of pertuzumab to T-DM $1 \pm$ taxane resulted in higher risks of diarrhea, rash and vomiting, which was consistent with the results in Phase Ila of the study by Krop et al. ${ }^{13}$ Martin et al ${ }^{14}$ also found higher severe/serious AE rates for the combination regimens and considered it as a result of overlapping toxicities. Despite the overlapping toxicities, interestingly, we found decreased risks of thrombocytopenia and grade $\geq 3$ increased AST in patients treated with the addition of pertuzumab. However, more studies are needed to clarify the event rate of AEs with the addition of pertuzumab to T-DM1 \pm taxane, due to the limited study size, small sample number and difference in the use of taxane.

With regard to the efficacy analysis, our pooled results showed that the addition of pertuzumab to T-DM1 \pm taxane showed noninferior, but not superior, ORR and CBR than did

Table 2 The outcomes of the patients in the included studies

\begin{tabular}{|c|c|c|c|c|c|c|c|}
\hline \multicolumn{8}{|c|}{ Controlled trials } \\
\hline \multirow[t]{2}{*}{ Study } & \multicolumn{4}{|l|}{ Treatment arm } & \multicolumn{3}{|c|}{ Control arm (without pertuzumab) } \\
\hline & ORR & CBR & \multicolumn{2}{|c|}{$\begin{array}{l}\text { Median PFS } \\
(95 \% \mathrm{Cl}) \text { (months) }\end{array}$} & ORR & CBR & $\begin{array}{l}\text { Median PFS } \\
(95 \% \mathrm{CI}) \text { (months) }\end{array}$ \\
\hline Gupta et al ${ }^{17}$ & $10.0 \%(2 / 20)$ & NR & NR & & $25.5 \%(\mid 3 / 5 I)$ & $39.2 \%(20 / 5 I)$ & $4.3(4-6.7)$ \\
\hline Krop et $\mathrm{al}^{13}$ & $52.4 \%(11 / 2 I)$ & $59.1 \%(13 / 22)$ & NE (5.8-NE) & & $47.6 \%(10 / 21)$ & $54.5 \%(12 / 22)$ & 7.4 (5.9-NE) \\
\hline Martin et al ${ }^{14, *}$ & NR & NR & NR & & $80.0 \%(20 / 25)$ & $92.0 \%(23 / 25)$ & $13.8(1.6-34)$ \\
\hline Perez et al ${ }^{15}$ & $64.2 \%(192 / 299)$ & $87.6 \%(262 / 299)$ & I5.2 (NR) & & $59.7 \%(181 / 303)$ & $84.5 \%(256 / 303)$ & I4.I (NR) \\
\hline \multicolumn{8}{|c|}{ Single-arm trials } \\
\hline Study & CR & \multicolumn{2}{|l|}{ PR } & SD & \multicolumn{2}{|c|}{ PD } & $\begin{array}{l}\text { Median PFS } \\
(95 \% \mathrm{CI}) \text { (months) }\end{array}$ \\
\hline Miller et $\mathrm{al}^{18}$ & \multirow{2}{*}{$\begin{array}{l}3(4.7 \%) \\
0(0 \%)\end{array}$} & \multicolumn{2}{|c|}{$23(35.9 \%)$} & $6(9.4 \%)$ & \multicolumn{2}{|c|}{$32(50.0 \%)$} & $6.6(4.21-9.46)$ \\
\hline Phillips et al ${ }^{12}$ & & \multicolumn{2}{|c|}{4 (44.4\%) } & $4(44.4 \%)$ & \multicolumn{2}{|c|}{ I (II.I\%) } & NR \\
\hline
\end{tabular}

Note: *Only the outcomes of the 25 patients with MBC.

Abbreviations: $C B R$, clinical benefit rate; $C R$, complete response; $M B C$, metastatic breast cancer; NE, not estimable; NR, not reported; ORR, objective response rate; PD, progressive disease; PFS, progression-free survival; PR, partial response; SD, stable disease. 


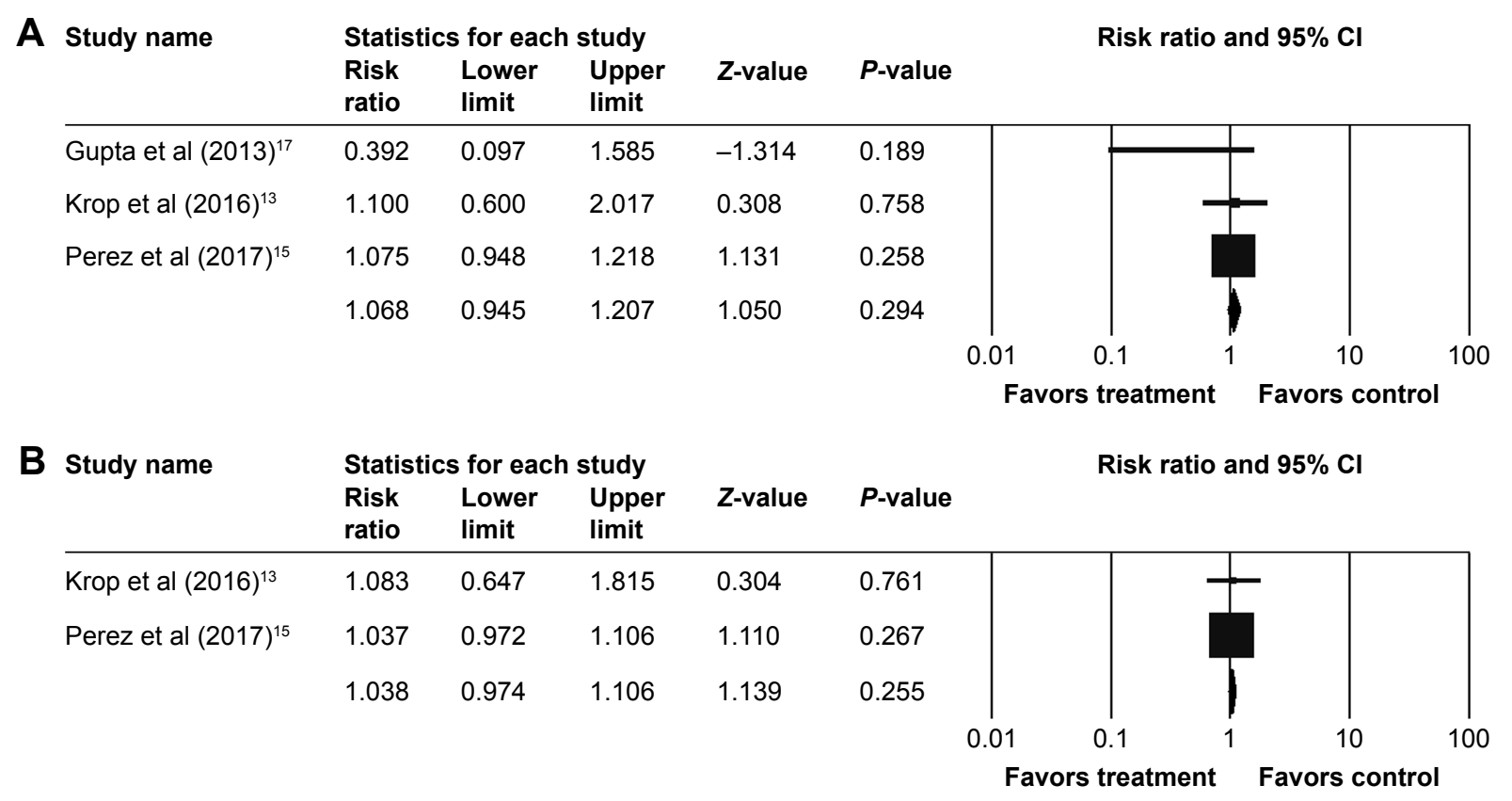

Figure 6 Forest plots of the RRs of ORR (A) and CBR (B) comparing the treatment group and control group (without pertuzumab) in controlled trials (fixed-effects models). Abbreviations: $C B R$, clinical benefit rate; ORR, objective response rate; RRs, relative risks.

A
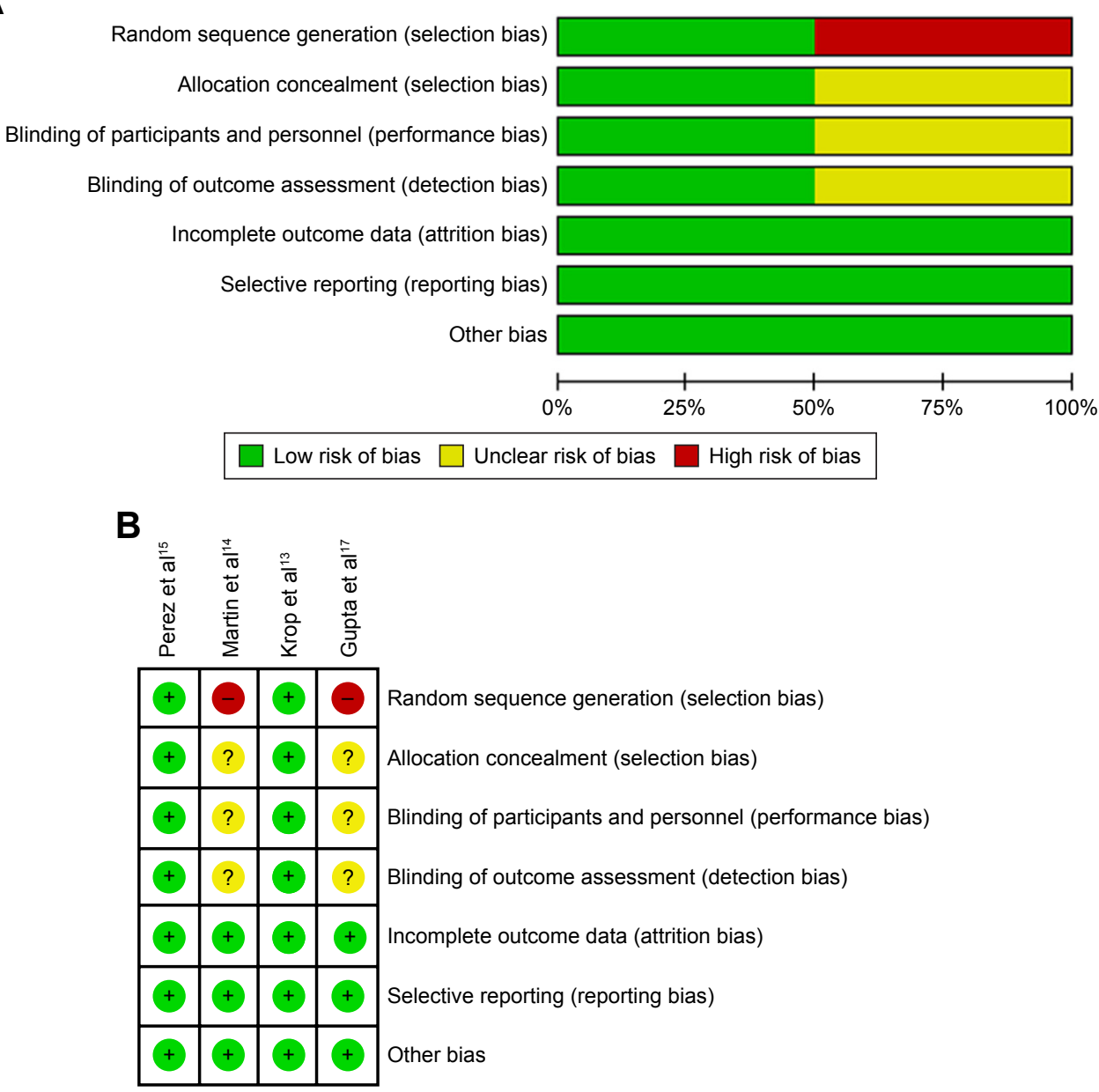

Figure 7 The risk of bias graph $(\mathbf{A})$ and the risk of bias summary $(\mathbf{B})$

Notes: Risk of bias graph: review of authors' judgments about each risk of bias item presented as percentages across all included studies. Risk of bias summary: review authors' judgments about each risk of bias item for each included study. 
T-DM1 \pm taxane. As mentioned earlier, the addition of pertuzumab to trastuzumab + docetaxel led to significant better survival outcomes in patients with previously untreated HER2positive MBC. ${ }^{10,11}$ Besides, preclinical studies have shown that pertuzumab could enhance the antitumor activity of T-DM1. ${ }^{12}$ However, recent clinical studies draw no definitive conclusions about the effect of adding pertuzumab to T-DM1 \pm taxane, and the researchers anticipated the results of the Phase III randomized trial (MARIANNE; ClinicalTrials.gov NCT01120184). ${ }^{12-14,17,18}$ Perez et $\mathrm{al}^{15}$ published the MARIANNE results, unexpectedly demonstrating that the addition of pertuzumab to T-DM1 did not improve PFS. Thus, further studies are warranted to explain and validate their results.

There are several limitations in our study. First, our metaanalysis was based on a limited number of clinical trials, and the sample size in most studies was small. Second, the study design of the included studies varied, with two RCTs, two nonrandomized clinical trials and two single-arm studies. Third, the treatment regimens were not exactly the same between the studies. Besides, few studies provided the PFS data and only the ORR and CBR were pooled. Furthermore, significant heterogeneity existed when analyzing some AEs. Thus, random-effects models were used to minimize heterogeneity. All of these limitations might lead to bias in our analysis. Therefore, caution should be applied with regard to our results, and many more studies are needed to further clarify the findings.

\section{Conclusion}

Common AEs, such as neurologic disorders, digestive disorders and hematologic disorders, should be carefully monitored in HER2-positive, LABC or MBC patients treated with $\mathrm{T}-\mathrm{DM} 1+$ pertuzumab \pm taxane. The addition of pertuzumab to T-DM1 \pm taxane showed noninferior, but not superior, ORR and CBR. However, due to the small sample size and heterogeneity of the included studies, the results should be treated with caution, and more studies are warranted to further assess the safety and efficacy of the addition of pertuzumab to $\mathrm{T}-\mathrm{DM} 1 \pm$ taxane.

\section{Acknowledgment}

This work was supported by the National Natural Science Foundation of China (NSFC 81602950).

\section{Disclosure}

The authors report no conflicts of interest in this work.

\section{References}

1. Slamon DJ, Clark GM, Wong SG, Levin WJ, Ullrich A, McGuire WL. Human breast cancer: correlation of relapse and survival with amplification of the HER-2/neu oncogene. Science. 1987;235(4785):177-182.
2. Ross JS, Slodkowska EA, Symmans WF, Pusztai L, Ravdin PM, Hortobagyi GN. The HER-2 receptor and breast cancer: ten years of targeted anti-HER-2 therapy and personalized medicine. Oncologist. 2009; 14(4):320-368.

3. Slamon DJ, Leyland-Jones B, Shak S, et al. Use of chemotherapy plus a monoclonal antibody against HER2 for metastatic breast cancer that overexpresses HER2. N Engl J Med. 2001;344(11):783-792.

4. Chari RV. Targeted cancer therapy: conferring specificity to cytotoxic drugs. Acc Chem Res. 2008;41(1):98-107.

5. Lewis Phillips GD, Li G, Dugger DL, et al. Targeting HER2-positive breast cancer with trastuzumab-DM1, an antibody-cytotoxic drug conjugate. Cancer Res. 2008;68(22):9280-9290.

6. Junttila TT, Li G, Parsons K, Phillips GL, Sliwkowski MX. TrastuzumabDM1 (T-DM1) retains all the mechanisms of action of trastuzumab and efficiently inhibits growth of lapatinib insensitive breast cancer. Breast Cancer Res Treat. 2011;128(2):347-356.

7. Verma S, Miles D, Gianni L, et al. Trastuzumab emtansine for HER2-positive advanced breast cancer. N Engl J Med. 2012;367(19): 1783-1791.

8. Krop IE, Kim SB, Gonzalez-Martin A, et al. Trastuzumab emtansine versus treatment of physician's choice for pretreated HER2-positive advanced breast cancer (TH3RESA): a randomised, open-label, phase 3 trial. Lancet Oncol. 2014;15(7):689-699.

9. Scheuer W, Friess T, Burtscher H, Bossenmaier B, Endl J, Hasmann M. Strongly enhanced antitumor activity of trastuzumab and pertuzumab combination treatment on HER2-positive human xenograft tumor models. Cancer Res. 2009;69(24):9330-9336.

10. Baselga J, Cortes J, Kim SB, et al. Pertuzumab plus trastuzumab plus docetaxel for metastatic breast cancer. N Engl J Med. 2012;366(2):109-119.

11. Swain SM, Baselga J, Kim SB, et al. Pertuzumab, trastuzumab, and docetaxel in HER2-positive metastatic breast cancer. $N$ Engl J Med. 2015;372(8):724-734.

12. Phillips GD, Fields CT, Li G, et al. Dual targeting of HER2-positive cancer with trastuzumab emtansine and pertuzumab: critical role for neuregulin blockade in antitumor response to combination therapy. Clin Cancer Res. 2014;20(2):456-468.

13. Krop IE, Modi S, LoRusso PM, et al. Phase $1 \mathrm{~b} / 2 \mathrm{a}$ study of trastuzumab emtansine (T-DM1), paclitaxel, and pertuzumab in HER2-positive metastatic breast cancer. Breast Cancer Res. 2016;18(1):34.

14. Martin M, Fumoleau P, Dewar JA, et al. Trastuzumab emtansine (T-DM1) plus docetaxel with or without pertuzumab in patients with HER2-positive locally advanced or metastatic breast cancer: results from a phase Ib/IIa study. Ann Oncol. 2016;27(7):1249-1256.

15. Perez EA, Barrios C, Eiermann W, et al. Trastuzumab emtansine with or without pertuzumab versus trastuzumab plus taxane for human epidermal growth factor receptor 2-positive, advanced breast cancer: primary results from the phase III MARIANNE Study. J Clin Oncol. 2017;35(2):141-148.

16. Moher D, Liberati A, Tetzlaff J, Altman DG. Preferred reporting items for systematic reviews and meta-analyses: the PRISMA statement. J Clin Epidemiol. 2009;62(10):1006-1012.

17. Gupta M, Wang B, Carrothers TJ, et al. Effects of trastuzumab emtansine (T-DM1) on QT interval and safety of pertuzumab plus T-DM1 in patients with previously treated human epidermal growth factor receptor 2-positive metastatic breast cancer. Clin Pharmacol Drug Dev. 2013; 2(1):11-24.

18. Miller KD, Dieras V, Harbeck N, et al. Phase IIa trial of trastuzumab emtansine with pertuzumab for patients with human epidermal growth factor receptor 2-positive, locally advanced, or metastatic breast cancer. J Clin Oncol. 2014;32(14):1437-1444.

19. Seidman AD, Berry D, Cirrincione C, et al. Randomized phase III trial of weekly compared with every-3-weeks paclitaxel for metastatic breast cancer, with trastuzumab for all HER-2 overexpressors and random assignment to trastuzumab or not in HER-2 nonoverexpressors: final results of Cancer and Leukemia Group B protocol 9840. J Clin Oncol. 2008;26(10):1642-1649.

20. Review Manager (RevMan) [Computer program]. Version 5.3. Copenhagen: The Nordic Cochrane Centre, The Cochrane Collaboration, 2014. 


\section{Publish your work in this journal}

Drug Design, Development and Therapy is an international, peerreviewed open-access journal that spans the spectrum of drug design and development through to clinical applications. Clinical outcomes, patient safety, and programs for the development and effective, safe, and sustained use of medicines are the features of the journal, which

has also been accepted for indexing on PubMed Central. The manuscript management system is completely online and includes a very quick and fair peer-review system, which is all easy to use. Visit http://www.dovepress.com/testimonials.php to read real quotes from published authors.

Submit your manuscript here: http://www.dovepress.com/drug-design-development-and-therapy-journal 